\title{
AVALIAÇÃO DA DEGRADAÇÃO DE FACHADAS DE EDIFÍCIOS: ESTUDO DE CASO EM SALVADOR/BA
}

\author{
WEYLL, KARLA PIANCHÃO \\ Engenharia Civil \\ Universidade Federal da Bahia \\ Bahia; Brasil \\ karla.weyll@gmail.com
}

\author{
BARBOSA, LUANNE BASTOS DE BRITTO \\ Mestranda em Engenharia Civil \\ Universidade Federal da Bahia \\ Bahia; Brasil \\ lubastosb@gmail.com
}

\author{
Doutoranda em Engenharia Civil \\ Universidade Federal da Bahia \\ Bahia; Brasil \\ milena.bsc@gmail.com
}

CERQUEIRA, MILENA BORGES DOS SANTOS

\author{
COELHO, VINÍCIUS ALMEIDA \\ Mestrando em Engenharia Civil \\ Universidade Federal da Bahia \\ Bahia; Brasil \\ mrvoelho@gmail.com
}

\author{
MARTINS, MATHEUS GOMES \\ Mestrando em Engenharia Civil \\ Universidade Federal da Bahia \\ Bahia; Brasil \\ matheus.engmartins@gmail.com
}

\author{
SILVA, FRANCISCO GABRIEL \\ SANTOS \\ Professor Doutor \\ Universidade Federal da Bahia \\ Bahia; Brasil \\ fgabriel.ufba@gmail.com
}

\section{RESUMO}

Tendo em vista à importância dos sistemas de revestimento e a frequente ocorrência de manifestações patológicas em fachadas de edificações, torna-se imprescindível o desenvolvimento de estudos com foco na identificação e no controle dos principais danos gerados. Este trabalho tem como objetivo a verificação das manifestações patológicas mais frequentes e suas prováveis causas, por meio da análise das principais ocorrências em fachadas de edifícios na cidade de Salvador/BA, além de relacionar a degradação da fachada com fatores como a orientação cardeal da fachada, região da fachada e distância em relação à orla marítima. O estudo de caso realiza-se com base em uma amostragem de edificações situadas em bairros distintos, a partir da realização de visitas para identificação das formas de degradação, mapeamento de fachadas e execução de diagnósticos, possibilitando uma comparação dos fatores que influenciam na ocorrência de determinadas manifestações e a percepção de formas de controle e prevenção para cada tipo de ocorrência. As manifestações patológicas detectadas neste estudo de caso foram o manchamento na pintura, fissura mapeada, descascamento da pintura e desplacamento cerâmico, enquanto as principais causas foram ações ambientais, falta de manutenção e falhas de projeto e execução.

Palavras-chave: fachada, degradação, patologia, vida-útil, desempenho.

\section{ABSTRACT}

Given the importance of cladding systems and the frequent occurrence of pathological manifestations in building façades, it is essential to develop studies focusing on the identification and control of the main damages generated. This paper aims to verify the most frequent pathological manifestations and their probable causes, through the analysis of the main occurrences in building facades in the city of Salvador / BA, and to relate the degradation of the facade with factors such as the cardinal orientation of the facade. , region of the facade and distance from the seafront. The case study is based on a sample of buildings located in different neighborhoods, from visits to identify the forms of degradation, mapping of façades and execution of diagnoses, allowing a comparison of factors that influence the occurrence of buildings. Certain manifestations and the perception of forms of control and prevention for each type of occurrence. The pathological manifestations detected in this case study were paint staining, mapped fissure, paint peeling and ceramic peeling, while the main causes were environmental actions, lack of maintenance and design and execution failures.

Keywords: facade, degradation, pathology, lifespan, performance. 


\section{INTRODUÇÃO}

É de conhecimento geral a importância dos sistemas de revestimento de fachadas de edifícios, embora na maioria dos casos os devidos cuidados em relação à execução e manutenção não sejam levados em consideração. A realização de manutenções preventivas e a utilização de materiais e métodos de execução condizentes com o ambiente em que estará exposta a edificação são fatores cruciais para um bom desempenho e, quando não realizados da maneira correta, levam à ocorrência das manifestações patológicas e à degradação das fachadas, gerando prejuízos estéticos e econômicos à edificação ou até mesmo causando acidentes. É necessário um conhecimento das principais causas das diversas formas de degradação e das características de cada manifestação patológica para que tais ocorrências sejam evitadas ou, no mínimo, para que sejam realizadas as devidas correções.

Para que atenda aos requisitos determinados, as fachadas devem ser executadas com a utilização de materiais condizentes com o projeto para evitar a ocorrência manifestações patológicas que atingem os revestimentos e podem causar prejuízos tanto à edificação quanto aos indivíduos que a frequentam.

Segundo Consoli (2006), a variação da temperatura é um dos agentes mais agressivos aos revestimentos de edifícios, levando ao aparecimento de fissuras, descolamentos e rupturas devido às variações físicas e químicas a que ficam sujeitos os materiais. Conforme Vilasboas (2013), Salvador possui um clima tropical caracterizado por altas temperaturas, alta umidade e sem ocorrência de estação seca.

Com o desenvolvimento de novas tecnologias, novos processos construtivos e diferentes materiais de construção que objetivam atender às crescentes demandas do mercado, com consumidores cada vez mais exigentes, é visível a necessidade de um maior controle no projeto e na execução das novas edificações para que todas as exigências sejam atendidas.

Segundo a NBR 5674:2012, manutenção é o conjunto de atividades a serem realizadas para conservar ou recuperar a capacidade funcional da edificação e de suas partes constituintes de atender as necessidades e segurança dos seus usuários.

Um dos fatores que ocasionam o agravamento das manifestações patológicas é a ausência de manutenções preventivas, sendo muito comum a ausência de planos de manutenção preventiva e a postergação na execução de reparos, levando a consequências econômicas, estéticas e ao comprometimento da segurança.

Serviços de manutenção mal executados e reparos paliativos tornam-se tão dispendiosos quanto o atraso na realização das intervenções, sendo, na maioria das vezes, pior do que não intervir.

Em cidades como Salvador, onde grande parte das edificações se localiza próximo à orla marítima, nota-se a ocorrência de manifestações patológicas em diversos trechos das fachadas. O clima tropical e a umidade elevada, características da cidade, favorecem a ocorrência de manifestações patológicas como o manchamento na pintura, consequência da presença de microrganismos, além de que, por ser uma cidade litorânea e urbanizada, apresenta-se bastante exposta aos agentes agressivos.

O estudo e o conhecimento das causas que levam à degradação e ao comprometimento do desempenho das edificações são cruciais para a compreensão de cada manifestação patológica e o ponto de partida para que sejam desenvolvidos mecanismos que evitem a sua ocorrência. Deve-se conhecer, primeiramente, as origens e os motivos que levam ao aparecimento da manifestação patológica para, assim, tratá-las de maneira correta.

Diante do cenário apresentado, o presente trabalho buscar analisar e estudar as manifestações patológicas com maior incidência nos revestimentos de fachadas de edifícios localizados em Salvador/BA com ênfase na deteç̧ão das principais formas de degradação.

\section{METODOLOGIA}

No presente trabalho foi realizado um estudo de caso, por meio da análise das manifestações patológicas que ocorrem nas fachadas de edificações da cidade de Salvador. 
O estudo de caso divide-se em três partes, sendo elas: a coleta dos dados, com levantamento de informações da edificação, como por exemplo, a idade, distância em relação ao mar, acabamento da fachada, bairro e número de pavimentos; o tratamento de dados, com apresentação do grau de deterioração das fachadas; e o diagnóstico com suas prováveis causas.

$\mathrm{Na}$ etapa de coleta de dados foram realizadas visitas às edificações escolhidas com a inspeção visual, realização de medições das fachadas e identificação das manifestações patológicas existentes. Além disso, foram elaborados croquis das fachadas para registro e quantificação das manifestações. Para a inspeção e o registro das manifestações patológicas visíveis foi utilizada a metodologia LEM - UnB.

\section{RESULTADOS E DISCUSSÕES}

Para o estudo de caso foram escolhidos três edifícios, A, B e C, em bairros distintos da cidade de Salvador/BA, sendo feita a coleta de dados preliminares, identificação e o mapeamento das manifestações patológicas para posterior quantificação, classificação das manifestações e análise dos resultados.

\subsection{Tratamento de dados}

Da Figura 1 à Figura 4 encontram-se os mapeamentos das manifestações patológicas em cada fachada dos edifícios, utilizados como base para a determinação do Fator de Danos em relação à orientação cardial e ao edifício em geral.

\subsubsection{Edifício A}

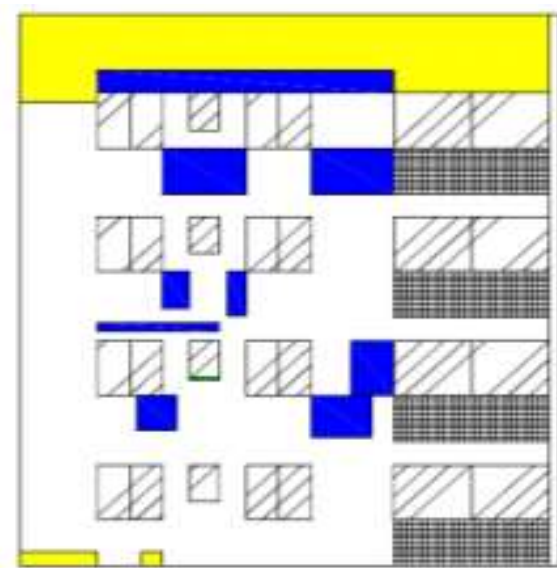

Manchamento na pintura

(bolor ou molo)

Descascamento de pintura

Fissura mapeada

Figura 1: Mapeamento das manifestações patológicas da fachada sudoeste do edifício A, sem escala

(AUTORES, 2020)

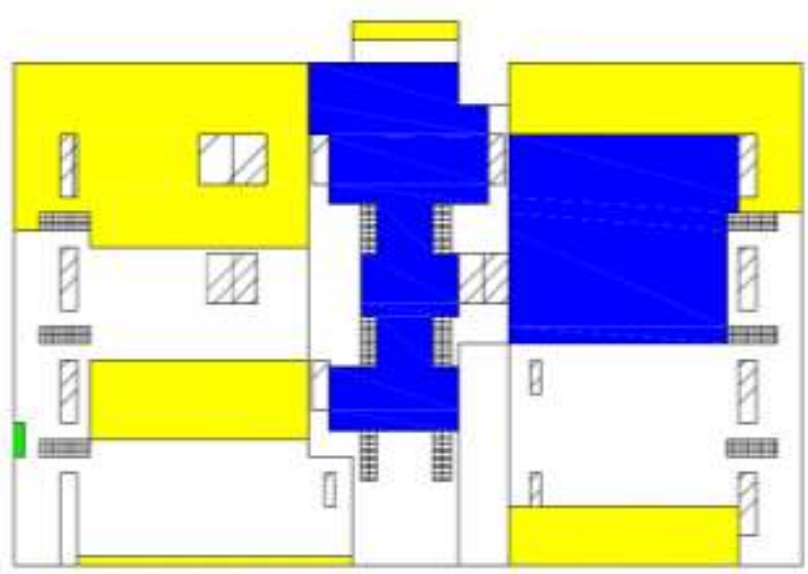

Aanchamento ra pintura (bolor os molo)

Descascamento de pintura

Fissure mageede

arstest . 

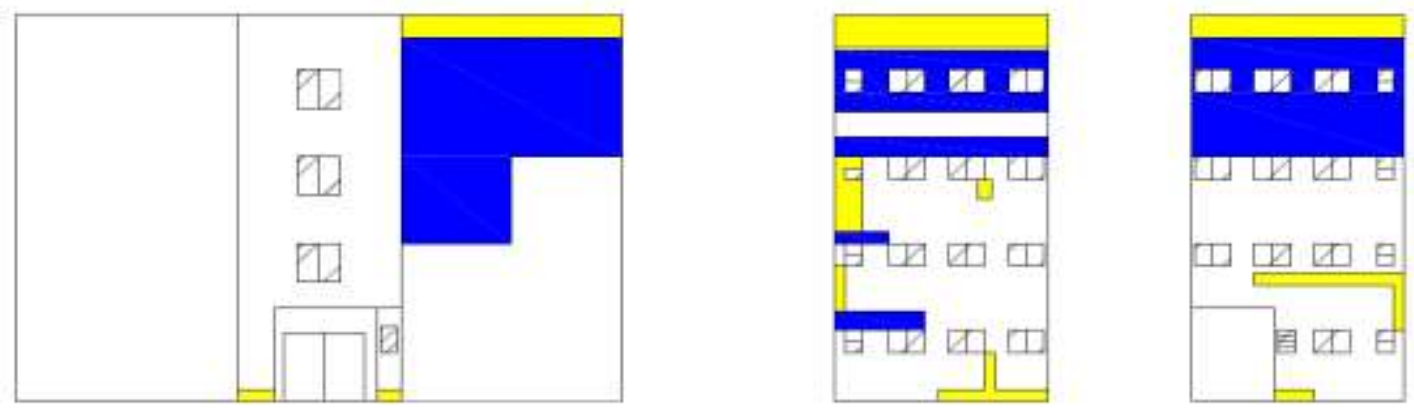

口Manchamento na pintura (bolor ou mofo)

Descascamento de pintura

E Fissura mapeada

Figura 3: Mapeamento das manifestações patológicas da fachada noroeste do edifício A, sem escala (AUTORES, 2020)

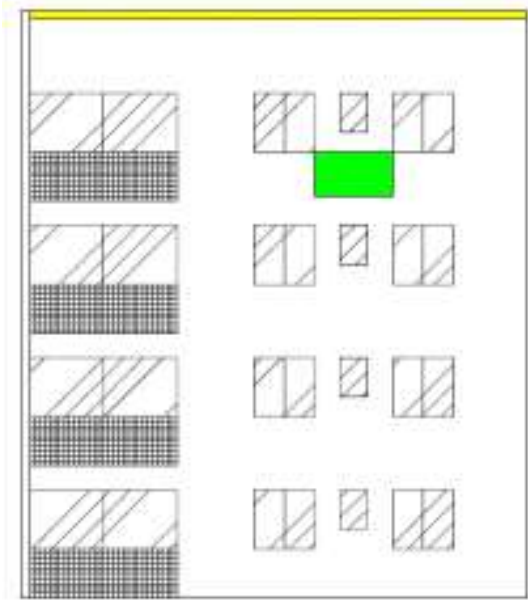

Manchamento na pintura

(bolor ou mofo)

Descascamento de pintura

Figura 4: Mapeamento das manifestações patológicas da fachada nordeste do edifício A, sem escala (AUTORES, 2020)

Nesta etapa foi feita a quantificação da ocorrência de manifestações patológicas e o cálculo do fator de danos de cada uma delas, por fachada. Para mensurar o primeiro estágio de degradação das fachadas, são apresentadas tabelas, com o Fator de Danos (FD), que relaciona a área das manifestações patológicas em função da área total da fachada, de acordo com a Equação 1 (SILVA, 2014).

$$
F D=\frac{A_{d}}{A}
$$

Sendo:

FD - Fator de Dano da fachada (\%);

Ad - Área de manifestação patológica observada na amostra de fachada $\left(\mathrm{m}^{2}\right)$;

A - Área total da amostra de fachada $\left(\mathrm{m}^{2}\right)$.

São apresentadas, no Quadro 1, as áreas de manifestação patológica em cada fachada e, a partir delas, o Fator de Dano de cada uma. 
Quadro 1 - Fator de Dano por fachada do edifício A.

\begin{tabular}{|c|c|c|c|}
\hline Fachada do edifício & $\begin{array}{c}\text { Área de manifestação } \\
\text { patológica }\left(\mathrm{m}^{2}\right)\end{array}$ & $\begin{array}{c}\text { Área total da fachada } \\
\left(\mathrm{m}^{2}\right)\end{array}$ & Fator de Dano da fachada \\
\hline Sudoeste & 24,58 & 123,96 & 0,20 \\
\hline Sudeste & 112,47 & 226,95 & 0,50 \\
\hline Noroeste & 90,84 & 363,6 & 0,25 \\
\hline Nordeste & 3,46 & 123,96 & 0,03 \\
\hline Edifício A & 231,35 & 838,47 & 0,28 \\
\hline
\end{tabular}

Comparando-se as fachadas, nota-se que as orientações sudeste $(0,50)$ e noroeste $(0,25)$ apresentam maior degradação do que as orientações sudoeste $(0,20)$ e nordeste $(0,03)$.

A figura 5 apresenta a ocorrência de manifestações patológicas, classificadas por tipo, do edifício A.

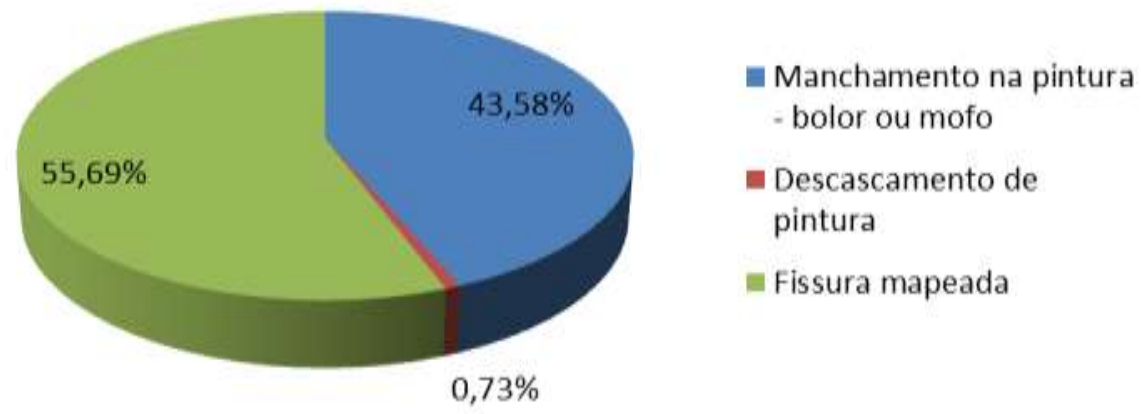

Figura 5: Ocorrência de manifestações patológicas global do edifício A

(AUTORES, 2020)

A partir dos dados expostos nota-se que em relação à edificação como um todo, a manifestação de maior expressividade é a fissura mapeada, com 55,69\% em relação à área total de manifestações patológicas. Não foram detectados problemas de descolamento e desplacamento cerâmico nas fachadas deste edifício.

\subsubsection{Edifício B}

Da Figura 6 à Figura 8 encontram-se os mapeamentos das manifestações patológicas em cada fachada do edifício, utilizados como base para a determinação do Fator de Danos em relação às regiões da fachada, à orientação cardial e ao edifício em geral.
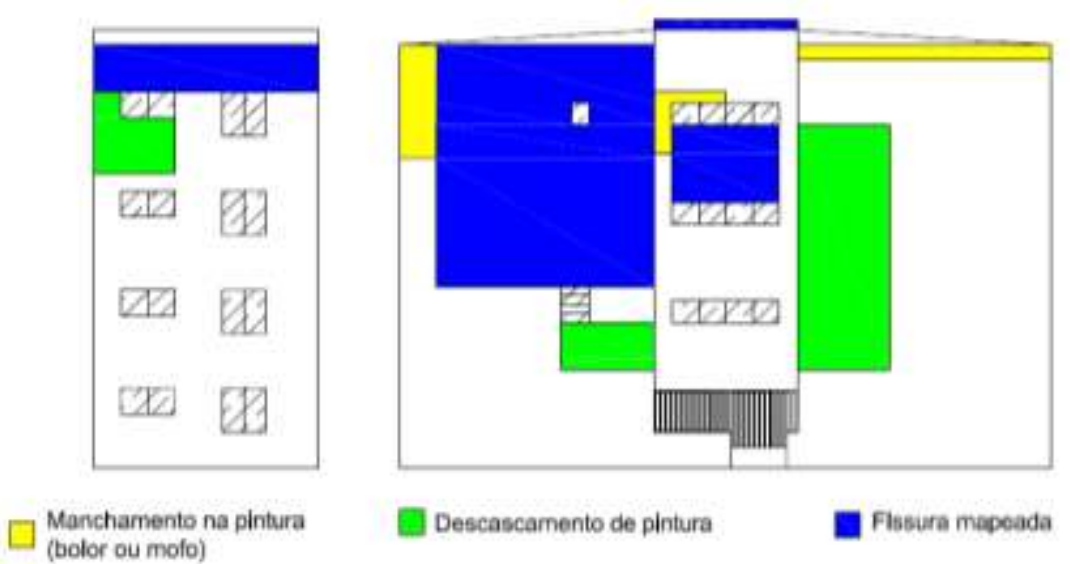

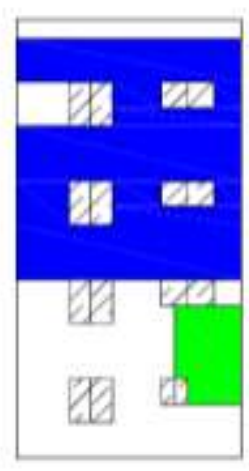

Desplacamento ceramico

Figura 6: Mapeamento das manifestações patológicas da fachada sudoeste do edifício B, sem escala (AUTORES, 2020) 

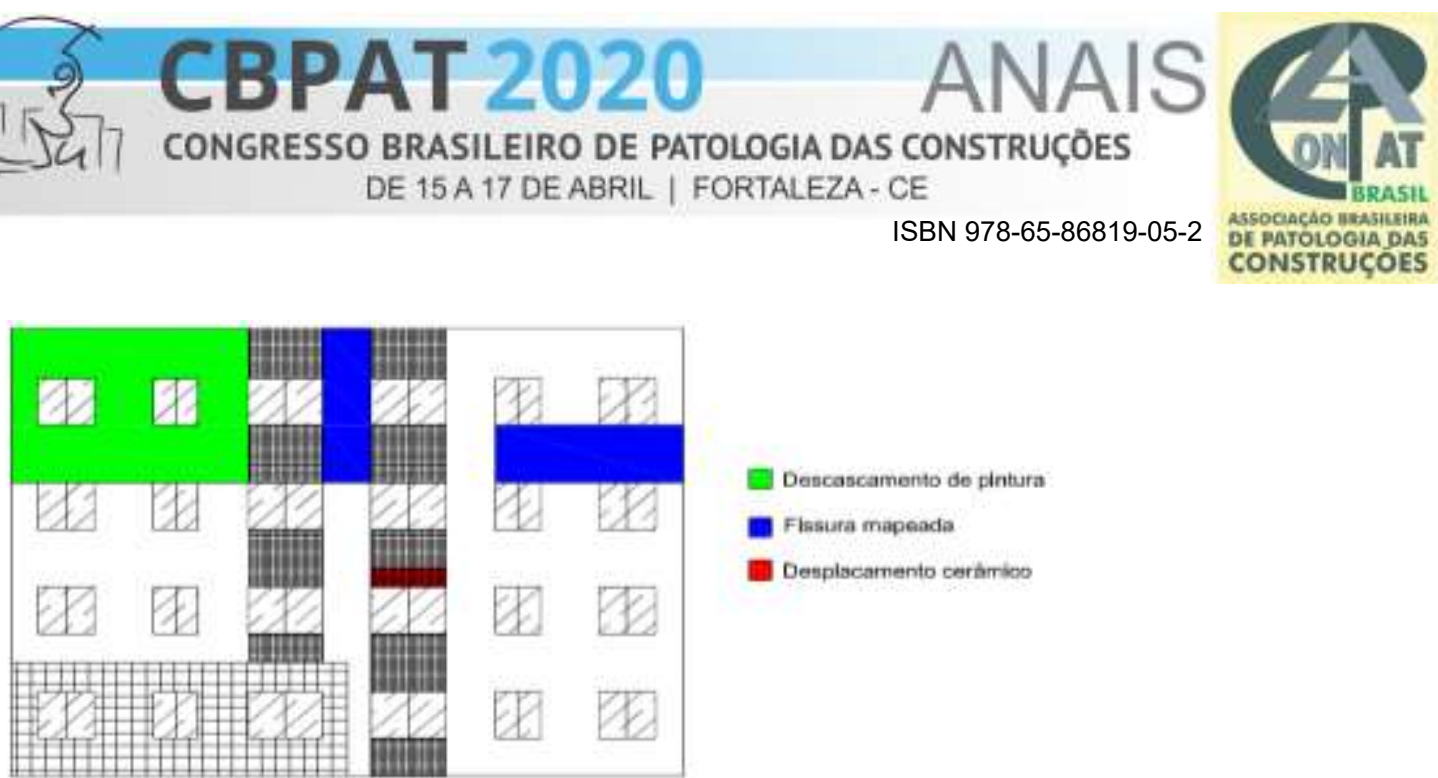

Descascamento de pintura

Fissura mapeade

Desplscarnento ceramicoo

Figura 7: Mapeamento das manifestações patológicas da fachada sudeste do edifício B, sem escala (AUTORES, 2020)

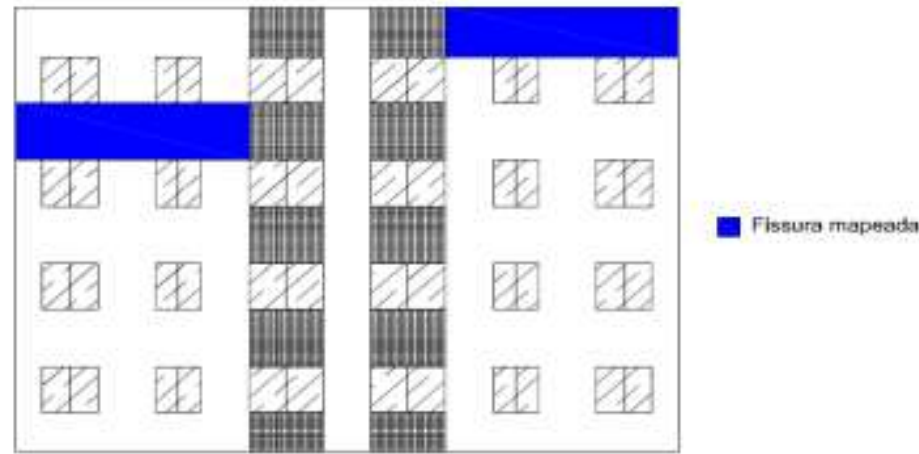

Figura 8: Mapeamento das manifestações patológicas da fachada noroeste do edifício B, sem escala (AUTORES, 2020)

São apresentadas, no Quadro 2, as áreas de manifestação patológica em cada fachada e, a partir delas, o Fator de Danos de cada uma. Comparando-se as fachadas, nota-se que a orientação sudoeste $(0,35)$ apresenta maior degradação do que as orientações sudeste $(0,17)$ e noroeste $(0,09)$.

Quadro 2 - Fator de Dano por fachada do edifício B.

\begin{tabular}{|c|c|c|c|}
\hline Fachada do edifício & $\begin{array}{c}\text { Área de manifestação } \\
\text { patológica }\left(\mathrm{m}^{2}\right)\end{array}$ & $\begin{array}{c}\text { Área total da fachada } \\
\left(\mathrm{m}^{2}\right)\end{array}$ & Fator de Dano da fachada \\
\hline Sudoeste & 127,19 & 367,99 & 0,35 \\
\hline Sudeste & 29,67 & 172,61 & 0,17 \\
\hline Noroeste & 14,7 & 172,61 & 0,09 \\
\hline Edifício B & 171,56 & 713,21 & 0,24 \\
\hline
\end{tabular}

A figura 9 apresenta a ocorrência de manifestações patológicas, classificadas por tipo, do edifício B.
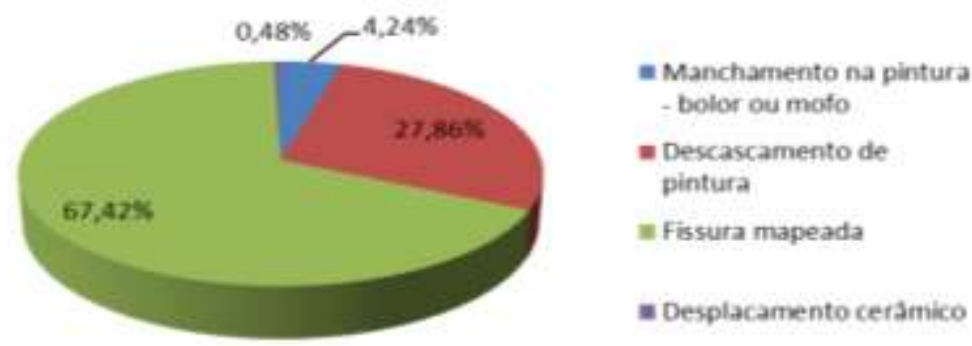

Figura 9: Ocorrência de manifestações patológicas global do edifício B (AUTORES, 2020) 
A partir dos dados expostos nota-se que a manifestação de maior presença é a fissura mapeada, com $67,42 \%$ em relação à área total de manifestações patológicas.

\subsubsection{Edifício C}

Da Figura 10 à 12 encontram-se os mapeamentos das manifestações patológicas em cada fachada do edifício, utilizados como base para a determinação do Fator de Danos em relação às regiões da fachada, à orientação cardial e ao edifício em geral.

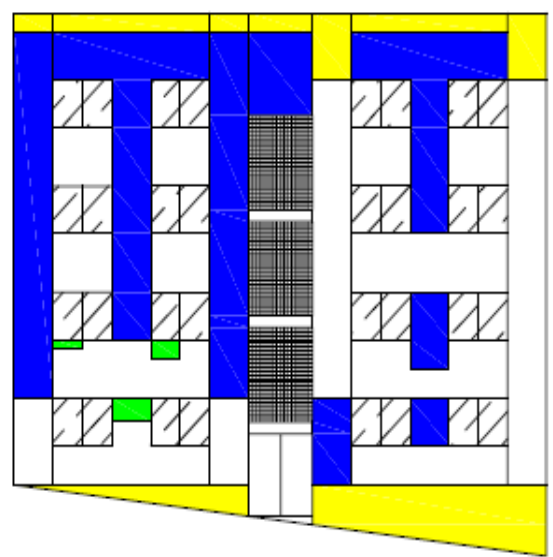

\section{$\square$ Manchamento na plntura (bolor ou mofo)}

$\square$ Descascamento de plntura

DFlssura mapeada

Figura 10: Mapeamento das manifestações patológicas da fachada oeste do edifício C, sem escala (AUTORES, 2020)

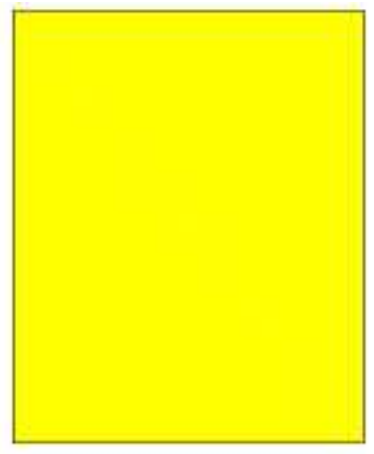

$\square$ Manchamento na pintura (bolor ou mofo)

Figura 11: Mapeamento das manifestações patológicas da fachada norte do edifício C, sem escala (AUTORES, 2020)

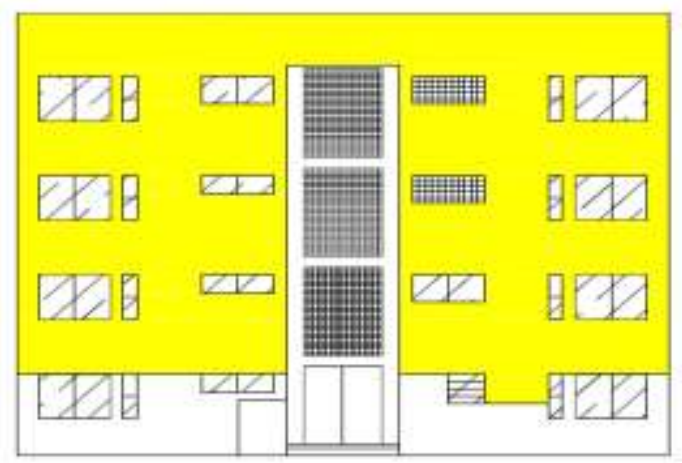

$\square$ Manchamento na pintura (bolor ou mofo)

Figura 12: Mapeamento das manifestações patológicas da fachada leste do edifício C, sem escala (AUTORES, 2020)

São apresentadas, no Quadro 3, as áreas de manifestação patológica em cada fachada e, a partir delas, o Fator de Danos de cada uma. Comparando-se as fachadas, nota-se que a orientação norte apresentou degradação em toda a fachada, enquanto as fachadas oeste e leste apresentam Fator de Dano de 0,39 e 0,59, respectivamente. 
Quadro 3 - Fator de Dano por fachada do edifício C.

\begin{tabular}{|c|c|c|c|}
\hline Fachada do edifício & $\begin{array}{c}\text { Área de manifestação } \\
\text { patológica }\left(\mathrm{m}^{2}\right)\end{array}$ & $\begin{array}{c}\text { Área total da fachada } \\
\left(\mathrm{m}^{2}\right)\end{array}$ & Fator de Dano da fachada \\
\hline Oeste & 75,65 & 193,64 & 0,39 \\
\hline Norte & 88 & 88 & 1,00 \\
\hline Leste & 105,72 & 180 & 0,59 \\
\hline Edifício C & 269,37 & 461,64 & 0,58 \\
\hline
\end{tabular}

A Figura 13 apresenta as porcentagens de ocorrência das manifestações patológicas em relação ao edifício C.

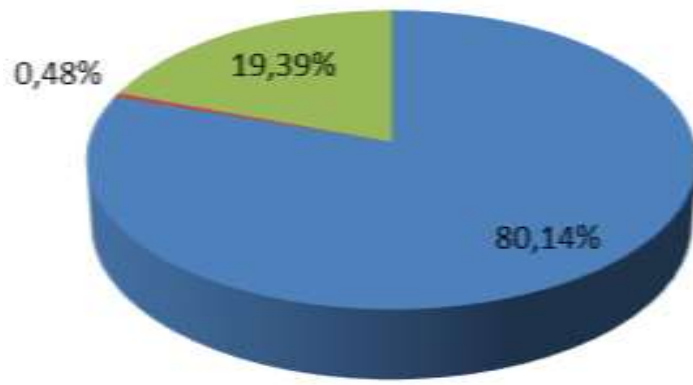

Manchamento na pintura

- bolor ou mofo

Descascamento de

pintura

in Fissura mapeada

Figura 13: Ocorrência de manifestações patológicas global do edifício C (AUTORES, 2020)

A partir dos dados expostos, nota-se que a manifestação de maior presença é o manchamento da pintura, com 80,14\% em relação à área total de manifestações patológicas devido à grande ocorrência nas fachadas norte e leste.

\subsubsection{Incidência de manifestações patológicas pela proximidade com o mar}

O Quadro 4 apresenta a relação entre o fator de dano calculado e a distância das edificações em relação ao mar.

Quadro 4 - Relação do Fator de Dano com a distância do mar para os edifícios A, B e C.

\begin{tabular}{|c|c|c|c|}
\hline & Edifício A & Edifício B & Edifício C \\
\hline Bairro & Pituaçu & São Marcos & Federação \\
\hline Distância do mar $(\mathrm{km})$ & 3,0 & 5,2 & 2,0 \\
\hline Fator de Dano $(\%)$ & 27,59 & 24,05 & 58,35 \\
\hline
\end{tabular}

Realizando-se a comparação entre as três edificações estudadas (Quadro 4), tem-se que o edifício C, localizado a $2 \mathrm{~km}$ do mar, apresentou Fator de Dano de 58,35\%, enquanto o edifício mais afastado da orla marítima, edifício B, apresentou Fator de Dano de 24,05\%. O edifício A, situado a $3 \mathrm{~km}$ do mar apresentou Fator de Dano de 27,59\%.

As edificações mais próximas do mar apresentaram maior degradação do que as que possuem um maior distanciamento. Para as edificações estudadas os valores de Fator de Dano obtidos foram condizentes com a relação distância/degradação, apesar de outros fatores também exercerem influência na deterioração das fachadas, como ações de manutenção, por exemplo.

\subsubsection{Incidência de manifestações patológicas por orientação cardeal da fachada}

A incidência de manifestações patológicas por orientação cardeal da fachada de cada edifício é apresentada na Figura 14. 

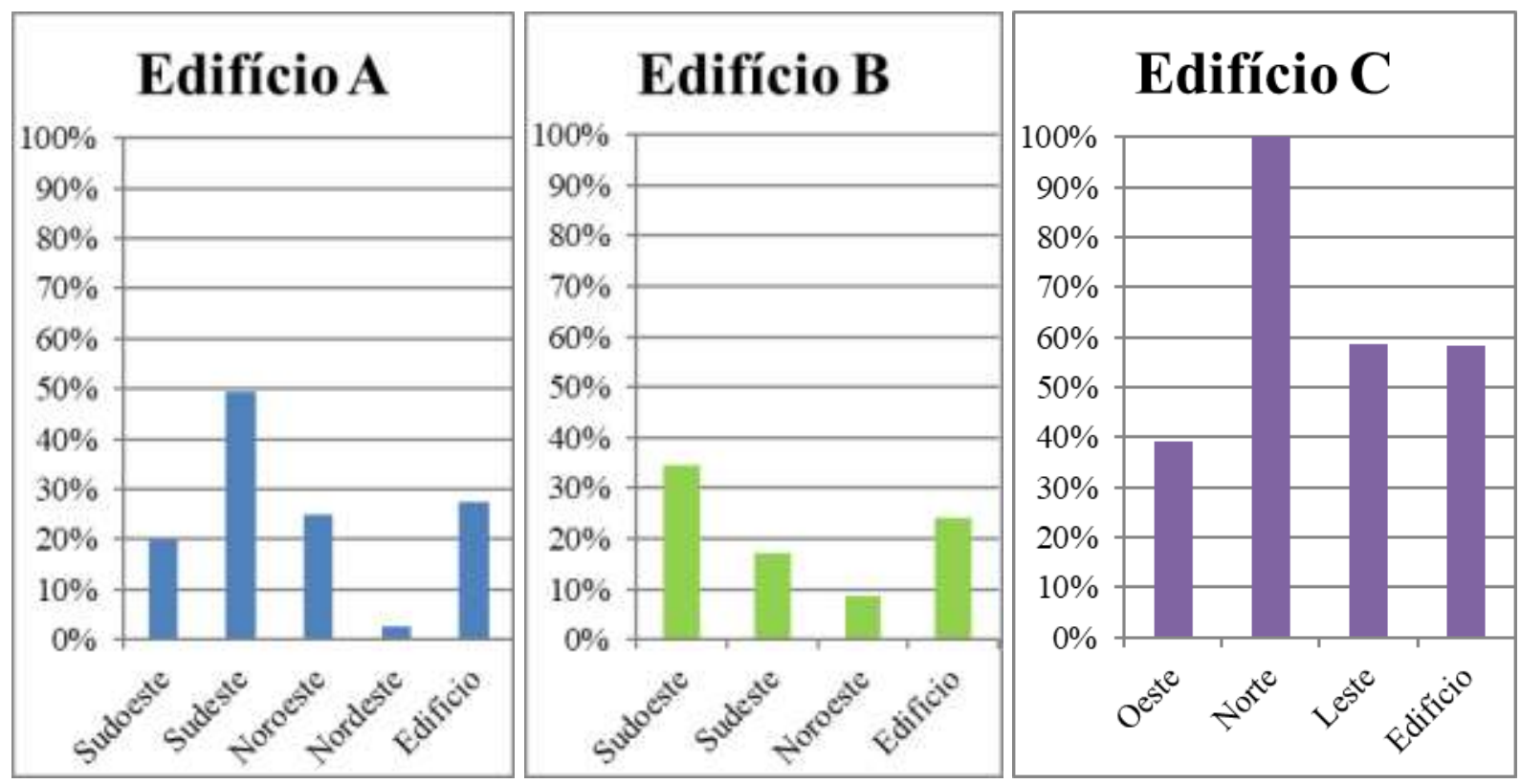

Figura 14: Fator de Danos dos edifícios A, B e C por orientação cardeal da fachada (AUTORES, 2020)

Para o edifício A houve maior degradação na fachada sudeste, enquanto o Edifício B apresentou maior degradação na fachada sudoeste e o edifício $\mathrm{C}$, com diferente disposição em relação aos primeiros, apresentou a fachada norte extremamente degradada, com a ocorrência de manchamento ao longo de toda sua extensão.

Como consequência dos diferentes métodos construtivos e das manutenções a que está submetida cada edificação (em alguns casos até mesmo não havendo manutenção), não foi possível correlacionar a orientação cardeal das fachadas com a degradação a que estão submetidas.

\subsubsection{Incidência de manifestações patológicas pela idade do edifício}

Em relação à idade das edificações (Quadro 5), a edificação mais antiga, edifício C, apresentou-se mais degradada, com Fator de Dano de 58,35\%, enquanto o edifício B, de menor idade em relação aos outros dois edifícios estudados, apresentou o menor Fator de Dano, com 24,05\%.

Quadro 5 - Relação do Fator de Dano com a idade dos edifícios A, B e C.

\begin{tabular}{|c|c|c|c|}
\hline & Edifício A & Edifício B & Edifício C \\
\hline Bairro & Pituaçu & São Marcos & Federação \\
\hline Idade (anos) & 40 & 36 & 45 \\
\hline Fator de Dano (\%) & 27,59 & 24,05 & 58,35 \\
\hline
\end{tabular}

\subsection{Diagnóstico}

A partir dos dados obtidos no estudo de caso, elaborou-se uma matriz de correlação causas prováveis / manifestação patológica baseada na ferramenta de Silvestre e Brito (2008), correlacionando as manifestações existentes nas fachadas dos edifícios com as suas causas mais prováveis (Quadro 6). 
Quadro 6 - Matriz de correlação causas prováveis / manifestação patológica.

\begin{tabular}{|c|c|c|c|c|}
\hline \multirow{2}{*}{\begin{tabular}{|c|} 
Causas \\
Prováveis
\end{tabular}} & \multicolumn{4}{|c|}{ Manifestação Patológica } \\
\hline & Fissura mapeada & $\begin{array}{l}\text { Manchamento na } \\
\text { pintura }\end{array}$ & $\begin{array}{l}\text { Descascamento da } \\
\text { pintura }\end{array}$ & $\begin{array}{l}\text { Desplacamento } \\
\text { cerâmico }\end{array}$ \\
\hline A1 & $\mathrm{x}$ & & $\mathrm{x}$ & \\
\hline A2 & & $\mathrm{x}$ & $\mathrm{x}$ & \\
\hline B1 & & & & $\mathrm{x}$ \\
\hline B2 & & & & $\mathrm{x}$ \\
\hline $\mathrm{C} 1$ & & $\mathrm{x}$ & $\mathrm{x}$ & $\mathrm{x}$ \\
\hline $\mathrm{C} 2$ & & & & $\mathrm{x}$ \\
\hline $\mathrm{C} 3$ & & & & $\mathrm{x}$ \\
\hline $\mathrm{C} 4$ & $\mathrm{x}$ & & & $\mathrm{x}$ \\
\hline $\mathrm{C} 5$ & $\mathrm{x}$ & $\mathrm{x}$ & $\mathrm{x}$ & $\mathrm{x}$ \\
\hline C6 & & $\mathrm{x}$ & $\mathrm{x}$ & $\mathrm{x}$ \\
\hline $\mathrm{D} 1$ & & $\mathrm{x}$ & $\mathrm{x}$ & \\
\hline \multicolumn{3}{|c|}{ A - Falhas de projeto } & \multicolumn{2}{|c|}{ C - Ações externas } \\
\hline \multicolumn{3}{|c|}{ A1 - Escolha de materiais incompatível, } & \multicolumn{2}{|c|}{$\mathrm{C} 1$ - Chuva dirigida } \\
\hline \multicolumn{3}{|c|}{ omissa ou não adequada à utilização } & \multicolumn{2}{|l|}{$\mathrm{C} 2$ - Vento } \\
\hline \multicolumn{3}{|c|}{ A2 - Ausência de pingadeiras } & \multicolumn{2}{|c|}{ C3 - Radiação solar } \\
\hline \multicolumn{3}{|c|}{ B - Falhas no processo executivo } & \multicolumn{2}{|c|}{ C4 - Choque térmico } \\
\hline \multicolumn{3}{|c|}{ B1 - Assentamento com filetes de arga- } & \multicolumn{2}{|c|}{ C5 - Focos de umidade } \\
\hline \multicolumn{3}{|c|}{ massa colante não esmagados ou mal es- } & \multicolumn{2}{|c|}{ C6 - Envelhecimento natural } \\
\hline \multicolumn{3}{|c|}{ palhados no tardoz } & \multicolumn{2}{|c|}{ D - Comportamento em uso } \\
\hline \multicolumn{3}{|c|}{ B2 - Espessura excessiva da argamassa de emboço } & \multicolumn{2}{|c|}{ D1 - Falta de manutenção } \\
\hline
\end{tabular}

A partir da matriz de correlação anomalias / causas prováveis nota-se que as manifestações patológicas não têm origem em uma causa isolada, mas em um conjunto de causas que levam ao seu aparecimento ou intensificação.

O manchamento na pintura, por exemplo, pode ser consequência de fatores como ausência de pingadeira, ocorrência de chuva dirigida, focos de umidade e, também, do envelhecimento natural e da falta de manutenção do edifício. Além disso, a ocorrência de apenas um desses fatores pode levar à ocorrência de mais de uma manifestação patológica, como os focos de umidade, causa provável para fissura mapeada, manchamento na pintura, descascamento de pintura e desplacamento cerâmico.

\section{CONCLUSÕES}

Diversos são os fatores que influenciam a ocorrência de manifestações patológicas, como pôde ser verificado ao longo do estudo de caso. Falhas de projeto, falhas no processo executivo, ações ambientais e falta de manutenção podem comprometer o desempenho e a durabilidade da edificação.

Para os três edifícios estudados, um grande problema foi detectado: a falta de manutenção, realidade de grande parte dos empreendimentos localizados em Salvador. A falta de manutenção é um dos principais fatores que intensificam a degradação dos edifícios e a falta de informação e de interesse dos usuários em relação à necessidade de realização de manutenções preventivas acabam por contribuir com a evolução acelerada dos danos. 
As manifestações patológicas detectadas nas três edificações foram manchamento na pintura (48,62\%), fissura mapeada $(43,63 \%)$, descascamento da pintura $(7,63 \%)$ e desplacamento cerâmico $(0,12 \%)$, atentando-se para o fato de as três edificações terem, majoritariamente, revestimento da fachada em pintura.

Relacionando-se a degradação das fachadas com a distância para o mar, obteve-se que o edifício de menor distanciamento (edifício C, com distância de 2,0 km) apresentou Fator de Dano de 58,35\%, enquanto o mais afastado (edifício B, com distância de 5,2 km) apresentou Fator de Dano de 24,05\%. Em relação à idade da edificação, o edifício mais antigo apresentou-se mais degradado em relação aos outros dois. Já em relação à orientação cardeal das fachadas, apesar de a quantificação dos dados ter sido realizada com base no posicionamento das fachadas, não foi possível estabelecer uma relação entre a orientação cardeal e sua degradação.

O Fator de Dano mostrou-se uma ferramenta útil na determinação da degradação, possibilitando uma visão geral da deterioração das fachadas. Com base nas informações coletadas foi possível realizar a quantificação da degradação e identificar os principais fatores envolvidos.

\section{AGRADECIMENTOS}

Agradecemos à Fundação de Amparo à Pesquisa do Estado da Bahia (FAPESB) pelo apoio fincanceiro e incentivo à pesquisa.

\section{REFERÊNCIAS}

ASSOCIAÇÃO BRASILEIRA DE NORMAS TÉCNICAS. NBR 5674: Manutenção de edificações - Procedimento. Rio de Janeiro, 2012.

CONSOLI, O. J. Análise da durabilidade dos componentes de fachadas de edifícios, sob a ótica do projeto arquitetônico. Dissertação (Mestrado), Universidade Federal de Santa Catarina, Florianópolis, 2006.

SILVA, M. DE N. B. Avaliação quantitativa da degradação e vida útil de revestimentos de fachada - aplicação ao caso de Brasília/DF. Tese (Doutorado) - Universidade de Brasília, Departamento de Engenharia Civil e Ambiental, Brasília, 2014.

SILVESTRE, J; BRITO, J. Inspeção e diagnóstico de revestimentos cerâmicos aderentes. Revista Engenharia Civil, Universidade do Minho, Portugal, 2008.

VILASBOAS, J. M. L. Estudo dos mecanismos de transporte de cloretos no concreto, suas inter-relações e influência na durabilidade de edificações na cidade de Salvador-BA. Tese (Doutorado) - Universidade Federal da Bahia. Escola Politécnica. Salvador, 2013. 